\title{
Study of Bacteria Growth for the Development of Bio-Mediated Soil Improvement Methods
}

\author{
Javier Rodriguez Corral ${ }^{1}$, Helen Mitrani ${ }^{2}$, Meng Zhang ${ }^{3}$, Martyn Dade-Robertson ${ }^{1}$ \\ ${ }^{1}$ School of Architecture, Planning and Landscape, Newcastle University \\ Newcastle upon Tyne, UK \\ J.Rodriguez-Corral2@newcastle.ac.uk; martyn.dade-robertson@newcastle.ac.uk \\ ${ }^{2}$ School of Engineering, Newcastle University \\ Newcastle upon Tyne, UK \\ helen.mitrani@newcastle.ac.uk \\ ${ }^{3}$ Department of Applied Sciences, Northumbria University \\ Newcastle upon Tyne, UK \\ meng.zhang@unn.ac.uk
}

\section{Extended Abstract}

Bio-mediated soil improvement techniques use biological processes to increase soil strength, reduce saturation or remove contaminants. These techniques can have advantages of reduced cost and lower environmental impact over traditional methods but more research is required to ensure effective application in practice. One such ground improvement technique is Microbially-Induced Calcite Precipitation (MICP) which uses the natural process of bacterial precipitation of calcium carbonate to bind soil grains together, increasing the strength and stiffness [1]. Ideally the bacteria should be homogeneously distributed within the soil volume and should survive long enough to produce a sufficient degree of cementation. However, bacteria in soils are naturally more prevalent near the surface of the soil, rather than at depth [2] and their growth is highly dependent on the space between soil grains and on environmental conditions such as $\mathrm{pH}$, temperature and availability of nutrients [3].

As part of a project to develop a new, responsive ground improvement technique, based on using engineered bacteria to cement soil in response to pressure [4], the effect of initial cell concentration, temperature and $\mathrm{pH}$ on the growth of $B$. subtilis on Petri dishes (35mm diameter) and in cylindrical volumes (35mm diameter and 100 $\mathrm{mm}$ high) of Agarose Low Melt (LM) gel has been studied. Agarose LM gel is used as a soil analogue in this study as it facilitates monitoring of the bacteria and improved control of environmental conditions. It also has similar relevant mechanical properties (permeability, pore size, shear strength) to clay soils [5]. To ensure a homogeneous initial distribution of the bacteria a method was developed where a solution of Agarose LM and nutrients was autoclaved then placed in a water bath at $40-45^{\circ} \mathrm{C}$ (just above the gelling temperature of the Agarose) and bacteria inoculated into the solution and thoroughly mixed. The Agarose was then refrigerated for a few minutes to allow gelation, then incubated at the desired temperature for bacteria growth. A Confocal Microscope (Leica TCS SPE) was used to image the bacteria colonies, which were counted using an image-processing software, ImageJ. To study the growth in the cylinders, 20 slices were taken and the bacteria counted in each. Growth curves were obtained by counting bacteria colonies after different lengths of time up to 24 hours.

It was found that on Petri dishes increased bacteria growth was observed with increased initial concentration of bacteria and with a more acidic environment (pH6) compared to a more alkali environment (pH8). Higher temperatures $\left(35^{\circ} \mathrm{C}\right.$ compared to $25^{\circ} \mathrm{C}$ ) also resulted in increased growth but followed by accelerated decay resulting in similar numbers of bacteria colonies after 24 hours. In 3D volumes, the growth was generally found to be reduced, due reduced oxygen availability and the limited space in the Agarose pores. The growth was also found to be uneven, with higher growth in the layers closest to the surface and bottom of the cylinder and reduced growth in the middle layers. Further work is necessary to study this in detail and also to investigate whether similar behaviour occurs in soils and at larger scales. Nevertheless, this initial work has significant implications for the use of bio-mediated soil improvement methods in practice and how their performance could be improved. 


\section{References}

[1] V. S. Whiffin, L. A. van Paassen, M. P. Harkes, "Microbial Carbonate Precipitation as a Soil Improvement Technique," Geomicrobiol. J., vol. 24, no. 5, pp. 417-423, 2007.

[2] W. B. Whiman, D. C. Coleman, W. J. Wiebe, "Prokaryotes: the unseen majority," Proc. Natl. Acad. Sci., vol. 95, no. 12, pp. 6578-6583, 1998.

[3] J. K. Mitchell, J. C. Santamarina, "Biological Considerations in Geotechnical Engineering," J. Geotech.Geoenviron. Eng., vol. 131, no. 10, pp. 1222-1233, 2005.

[4] M. Dade-Robertson, H. Mitrani, J. Rodriguez-Corral, M. Zhang, L. Hernan, A. Guyet, A. Wipat, “Design and Modelling of an Engineered Bacteria-based, Pressure-sensitive Soil," Bioinspiration and Biomimetics, vol.13, no.4, 046004, 2018.

[5] J. Rodriguez-Corral, H. Mitrani, M. Dade-Robertson, M. Zhang, "Agarose Gel as a Soil Analogue for Novel Ground Improvement Applications," in Proceedings of the 3rd World Congress on Civil, Structural, and Environmental Engineering (CSEE'18), Budapest, Hungary, 2018. 